\title{
Automation for Localization of Airsense
}

\author{
Gopichand Merugu, I.Krishnaveni
}

\begin{abstract}
AirSense technology is a network of High Sensitivity Smoke Detectors including HSSD2, and StratosMicra100 etc. and is catered to multiple regions. High Sensitivity Smoke Detector (HSSD) uses aspirating smoke detection. Aspirating Smoke Detection is a method of smoke detection that uses an aspirating fan to draw air from the protected area via a network of sampling pipes and sampling holes, and analyzes at the aspirating detector for the presence of smoke. UTC Climate Controls Security is a market leader in the manufacture of Aspirating Smoke Detectors (ASD). AirSense technology is capable of 16 loops, each loop with maximum of 127 detectors. These detectors are capable of providing the highest levels of sensitivity in environments such as production sites, paper mills, historic buildings, atrium buildings. This product uses three software applications like PipeCad, Remote and SenseNET. As the product is aimed for use across multiple regions, it is developed in 16 different languages. As a part of product testing, localization testing is taking more time to verify the correctness of strings with 16 languages. Hence the intent to go for automation is to reduce time to market and increase test coverage. This paper presents an automated testing performed on localization of AirSense product as to reduce the manual testing time. Visual studio Coded UI has been identified as a tool to develop the scripts. Scripts are being developed which run in un-attended mode. By this, the manual test time is estimated to reduce significantly.
\end{abstract}

\section{Keywords : Airsence, Localization, Testing.}

\section{INTRODUCTION}

The increase in the demand for secure life safety systems has brought about a revolution in the history of electronics, leading to many inventions. One such invention is fire protection system. The traditional fire alarm systems detect the occurrence of fire; notify the same to the end user, and process accordingly so as to suppress the same. There are several types of detectors to detect the fire. As this is a life safety product, it to be in market should undergo some standards of testing. This chapter explains an existing problem with the testing, followed by introduction to fire alarm control panels, detectors and, organization of the thesis so as to meet the problem statement. A fire alarm system is intended to detect fire at early stage. This helps the people to escape from the fire or by the fire being extinguished.

The effectiveness of the fire detection and alarm system usually depends on the stage of the fire at which it is operated.

The role of fire detection and alarm systems is to identify a developing fire emergency in a timely manner and to alert the building's occupants and fire emergency organizations. Fire alarm systems can include alarm initiating devices, alarm notification appliances, control units, fire safety control devices, annunciators, power supplies and wiring.

Revised Manuscript Received on September 10, 2019.

Gopichand Merugu, Professsor \& Head, Department of Information Technology, Vardhaman College of Engineering, Hyderabad, Telangana, India.

(E-mail: Gopi_merugu@yahoo.com.)

I.Krishnaveni, Quality Engineer, UTRC, Hyderabad, Telangana, India.
Typical control panel is shown in Figure 1.1. The control panel periodically monitors the states of the input devices like detectors, PULL station circuits, modules, etc. and accordingly trigger the output circuits as per their correlation with the input.

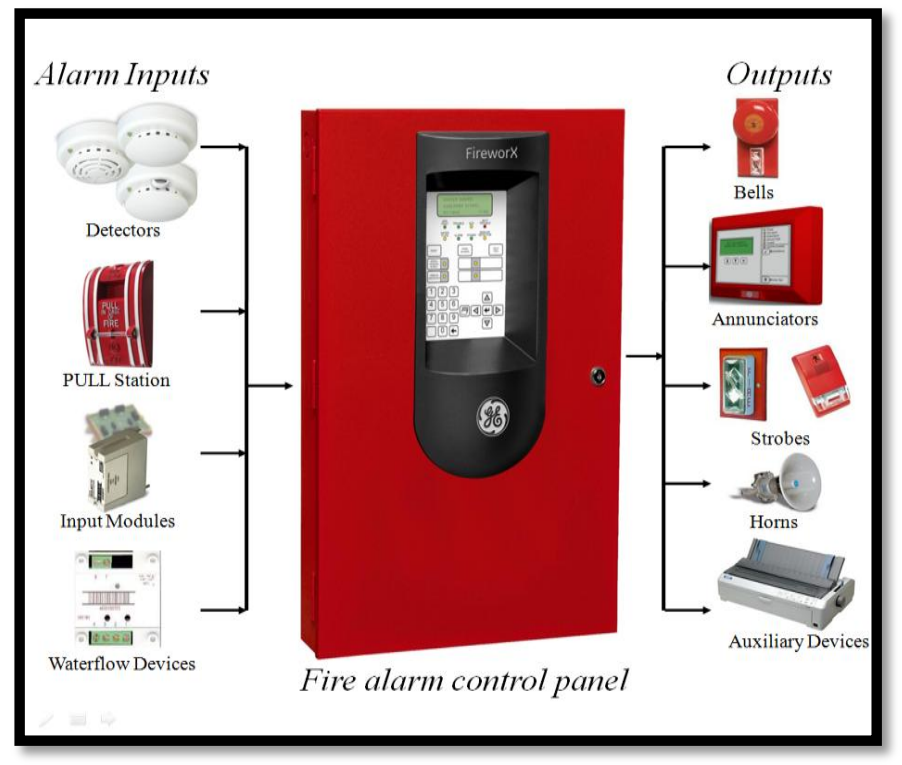

Figure 1: Fire Alarm Control Panel

AirSense technology is a network of HSSD detectors including HSSD2, and Stratos-Micra100 etc. This network is capable of 16 loops, each loop with maximum of 127 detectors. These detectors are capable of providing the highest levels of sensitivity in environments such as production sites, paper mills, historic buildings, atrium buildings.

High sensitivity smoke detector uses aspirating smoke detection (also known as air sampling), a method of smoke detection that uses an aspirating fan to draw air from the protected area via a network of sampling pipes and sampling holes, and analyzes at the aspirating detector for the presence of smoke.

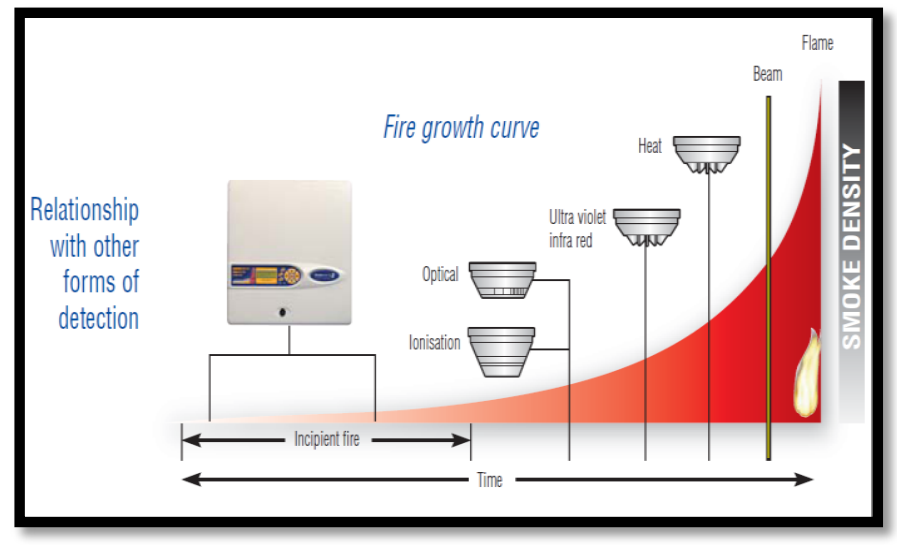

Figure 2 :Fire Detection Phase

Published By: Blue Eyes Intelligence Engineering 
Three types of software applications are used to assist in the design of sample pipe layouts and monitor configure AirSense installation sites. 1. PipeCAD 2..Remote and 3. SenseNET

\section{PipeCAD-PipeCAD}

is a Windows based that is used to model the aspirating smoke detector and sampling pipe network and predict performance.

The program allows the designer to draw a schematic view in three dimensions on the screen by use of a 3D snap grid. System layouts may be modified, stored, retrieved, and evaluated to provide optimum performance of the area to be protected.

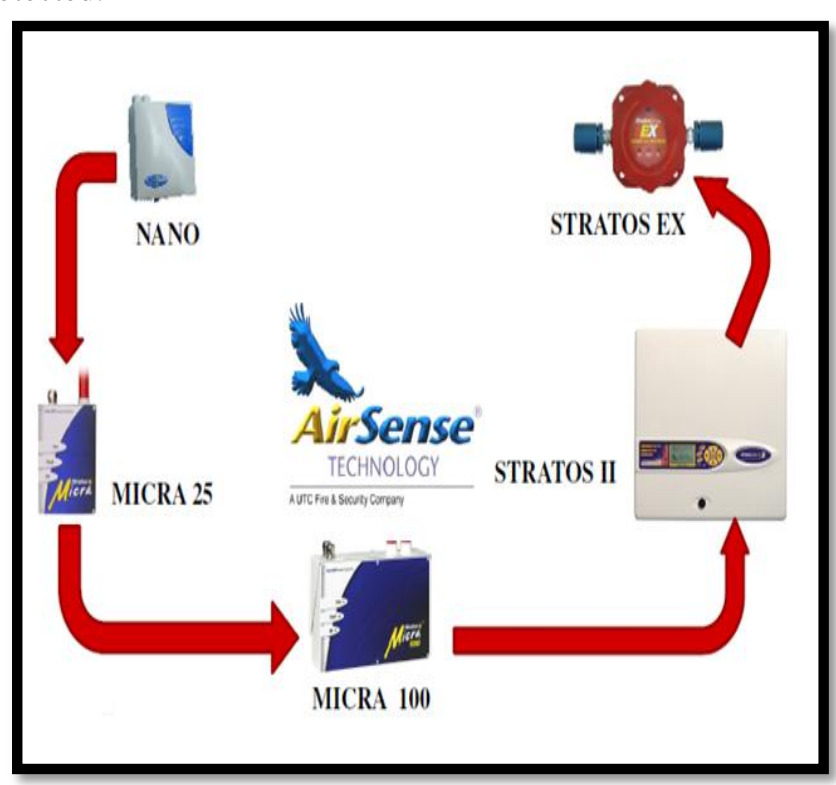

Figure 3:HSSD Portfolio

\section{Remote}

Remote is a windows based program which allows users to access the detectors built-in event logging, program the unit or use diagnostic facilities which check all of the major system circuits for correct operation with extensive built-in help. The remote control software lets the user configure and monitor function and option settings for the detectors and the command module form a desktop computer.

\section{Sensenet}

Sensenet is a windows based program that provides central management and monitoring of multiple loops, each with up to 127 detectors. The sensenet loops are highly fault tolerant and incorporate signal verification and error checking algorithms for the utmost in reliability.

As the product is developed in 16 different languages, manual testing is consuming plenty of time and manual effort, so a survey is conducted so as to build an automation script that can be executed in an un-attended mode.

testing approach - testing approach details about the testing methodologies and the testing techniques. As a methodology is chosen for software development, similarly a methodology is chosen for testing.

Testing methodologies: a methodology is a package of methods which includes of practical ideas and proven practices. Each testing methodology has its own merits and de-merits. Selection of a particular testing methodology depends on many factors like, client requirement, nature of project, project schedule, etc..

\section{PROPOSED SYSTEM}

The manual verification for the correctness of strings in 16 different languages with three software applications is a time consuming task. Hence the intent to go for automation will help in reducing the manual testing efforts and time as a result increase time for test coverage. The proposed system includes performing an automated localization testing on three software applications. This helps in reusability of the code and easy maintenance of scripts. The major advantage is it reduces time and human effort. Automation increases the quality by increasing the test coverage and maintenance of the scripts. To automate the application, a framework has to be designed which will give more flexibility for further enhancement of scripts. Scripts need to be developed which run in un-attended mode.

\section{A. system architecture}

A generic framework is designed, so that it supports the different applications with minor changes. Hybrid framework is chosen for developing the scripts. In the hybrid framework, frameworks used are key-word driven frame work and data driven frame work. Key-word driven frame work is used for the functional flow of each application. And data driven frame work is used for taking the expected results for comparison. Test automation framework improves the scalability, efficiency of test automation and also helps to reduce the test maintenance overhead by sharing automation scripts, enabling reuse and flexible sharing of test data. We can implement more frequent test cycles at lower cost.

\section{automation framework for localization testing}

Hybrid automation framework (a combination of datadriven and keyword driven) is used as framework for automation of localization testing. Keyword driven automation framework is used to make the code application independent. For verification of the result, data-driven automation frame work is used. The framework consists of the basic components given below

$$
\begin{array}{ll}
\text { 1. } & \text { Control file } \\
\text { 2. } & \text { Test case file } \\
\text { 3. } & \text { Startup script } \\
\text { 4. } & \text { Driver script } \\
\text { 5. } & \text { Utility script }
\end{array}
$$

\section{Control File}

- Consists details of all the test scenarios to be automated

- User will be able to select a specific scenario to execute based on turning on or off a flag in the control file

- Control file is in the form of an excel worksheet and contains columns for scenario id, execute $(y / n)$, object repository path, test case file path 


\section{Test Case File}

- $\quad$ Contains the detailed steps to be carried out for the execution of a test case

- It is also in the form of an excel sheet and contains columns for keyword, object name, parameter

\section{3. startup script}

- The starup script is utilized for the initialization and reads the control files

- It then calls the driver script to execute all the scenarios marked for execution in the control file

\section{4. driver script}

- It reads the test case files. Checks the keywords and calls the appropriate utility script functions based on specific keyword

- $\quad$ Error handling is taken care of in the driver script

5. utility scripts applications. It should not be application dependent

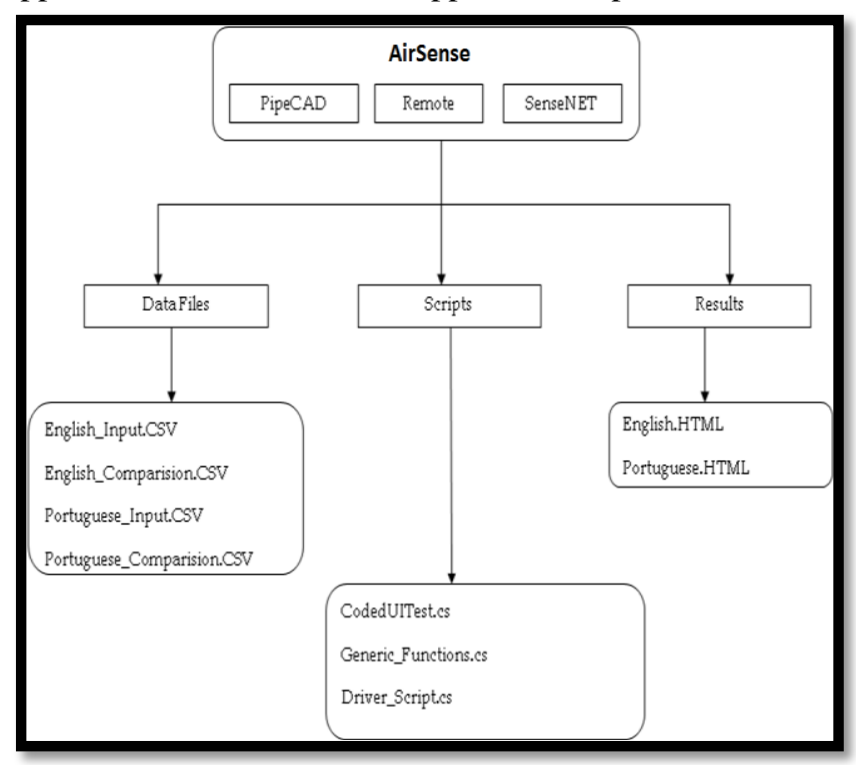

figure 4: generic framework of the application

\section{IMPLEMENTATION AND RESULTS}

Automated tests for user interface can be created using visual studio 2010 premium or visual studio 2010 ultimate. These are known as coded user interface tests. These coded ui tests are useful for functional testing of user interface and validation of user interface controls. Automated ui tests enable to test that the ui is functioning correctly after code changes. Coded ui tests are quicker to run than manual tests and can run them more frequently.

Automated tests that drive your application through its user interface (ui) are known as coded ui tests (cuits). These tests include functional testing of the ui controls. Coded ui tests are particularly useful where there is validation or other logic in the user interface. They are also frequently used to automate an existing manual test.

All the controls in the application are captured and played back, by recording i.e., the entire mouse clicks and the keyboard strokes can be recorded [7, 9], but, on the contrary the script generated by tool is huge and also
- Perform generic tasks that can be used across

difficult to understand for the user. To address this issue, we created a generic framework for each and every control. This framework is easy to understand and can be used for any application..the controls/objects in the application were identified by the window name, then using unique control id, the name and the control name. Here the input can be taken from the data table or can be hard coded in the script and the output can be reported in the xml file/excel file.

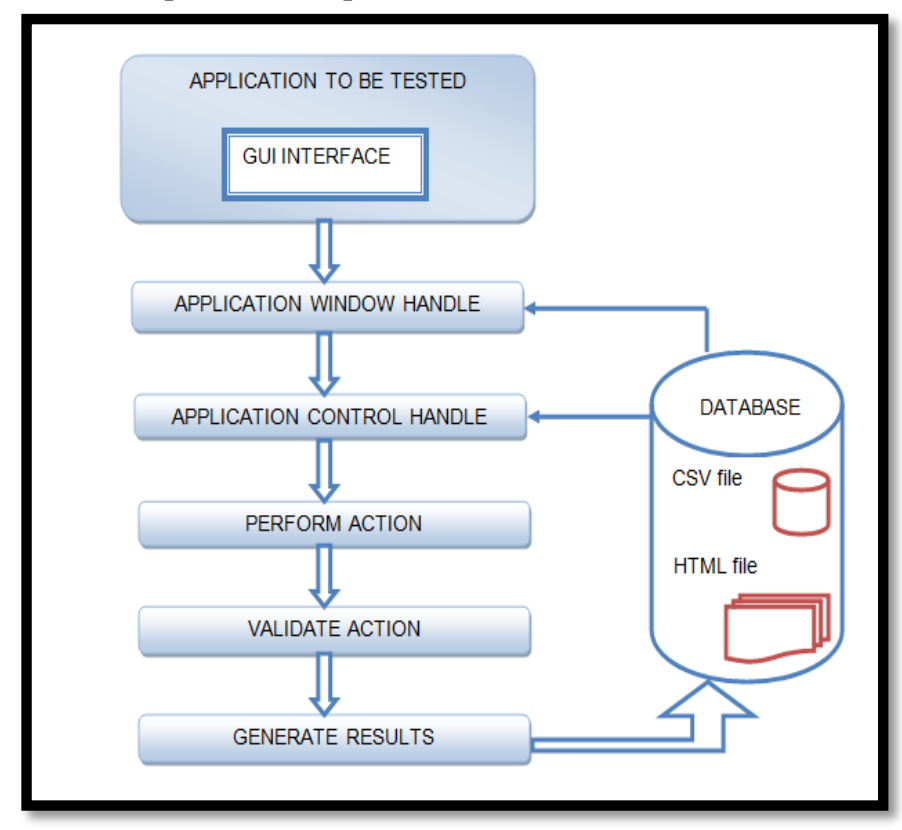

figure 5: the script execution flow using coded ui

To get better reusability of code instead of dumping all the code into one single class, different classes are created according to the functionality. All the functions that are generalized are placed in a single class file called "generic_functions.cs", similarly there are other class files in the project. In remote control software application, all the strings are checked for correctness in 16 different languages. For ex: when the application is set to portuguese language, the events $\log$ window is displayed as shown in figure

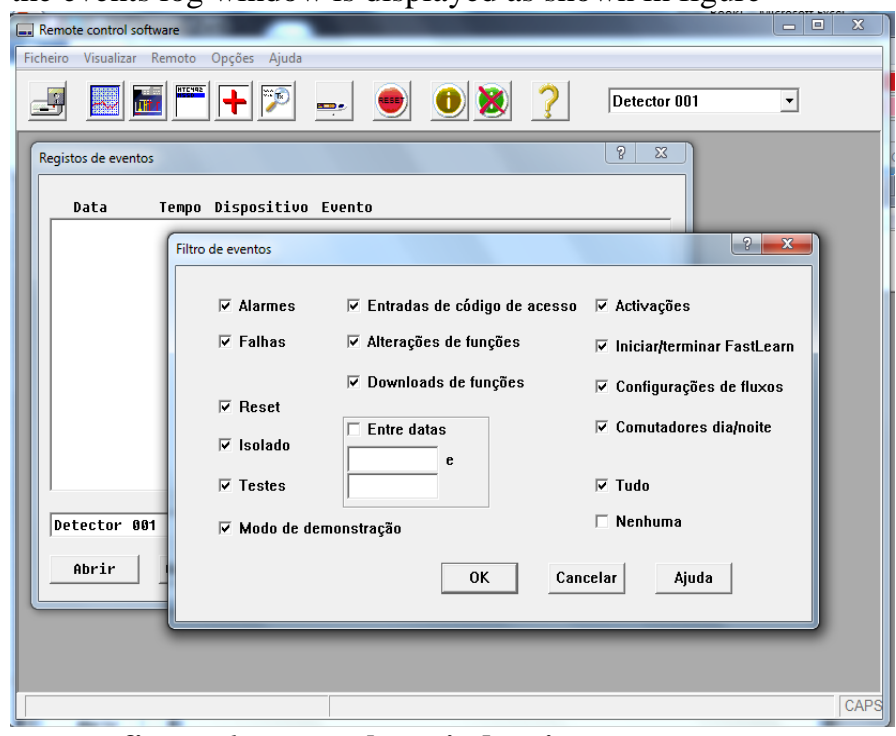

figure 6 : events log window in portuguese 
After The Script Execution, The Results File Is Generated In Html File And Is Shown In Figure

\begin{tabular}{|c|c|c|c|}
\hline \multicolumn{4}{|c|}{ Portuguese } \\
\hline Functionality Name & Expected Value & Obserred Value & Result \\
\hline View - Event Logs - Filter - Window & Reset & Reset & Pass \\
\hline View - Event Logs - Filter - Window & Isolado & Isolado & Pass \\
\hline View - Event Logs - Filter - Window & Testes & Testes & Pass \\
\hline View - Event Logs - Filter - Window & Alarmes & Alarmes & Pass \\
\hline View - Event Logs - Filter - Window & Fallhas & Fallhas & Pass \\
\hline View - Event Logs - Filter - Window & Comutadores dia/noite & Comutadores dia/noite & Pass \\
\hline View - Event Logs - Filter - Window & Iniciarterminar FastLearn & Iniciartterminar FastLearn & Pass \\
\hline View - Event Logs - Filter - Window & Alteraçòes de funçōes & Alteraçōes de funçòes & Pass \\
\hline View - Event Logs - Filter - Window & Configuraçòes de fluxos & Configuraçòes de fluxos & Pass \\
\hline View - Event Logs - Filter - Window & Modo de demonstraçàio & Modo de demonstraçàa & Pass \\
\hline View - Event Logs - Filter - Window & Entradas de código de acesso & Entradas de código de acesso & Pass \\
\hline View - Event Logs - Filter - Window & Downloads de funçòes & Downloads de funçòes & Pass \\
\hline View - Event Logs - Filter - Window & Activaçōes & Activaçōes & Pass \\
\hline View - Event Logs - Filter - Window & Tudo & Tudo & Pass \\
\hline View - Event Logs - Filter - Window & Nenhuma & Nenhuma & Pass \\
\hline View - Event Logs - Filter - Window & $\mathrm{OK}$ & $\mathrm{OK}$ & Pass \\
\hline View - Event Logs - Filter - Window & Cancelar & Cancelar & Pass \\
\hline View - Event Logs - Filter - Window & Ajuda & Ajuda & Pass \\
\hline View - Event Logs - Filter - Window & Entre datas & Entre datas & Pass \\
\hline View - Event Logs - Filter - Window & 21-09-1965 00:00:00 & $21 / 09 / 1965$ & Fail \\
\hline View - Event Logs - Filter - Window & 21-09-1965 00:00:00 & 21/09/1965 & Fail \\
\hline View - Event Logs - Filter - Window & Framel & Framel & Pass \\
\hline View - Event Logs - Filter - Window & e & e & Pass \\
\hline
\end{tabular}

figure 7: results for event logs window in portuguese

\section{CONCLUSIONS AND FUTURE WORK}

Airsense technology is a network of hssd detectors and is catered to multiple regions. Three software applications are used to monitor and configure the hssd range of detectors. These applications are developed in 16 different languages. As part of product testing, localization testing is consuming more time compared to functional testing thereby decreasing time for test coverage, and this test needs to be performed for all the iterations in software development as this is a life safety product.

Automation for localization testing of three software applications in 16 languages on 4 operating systems decreases the manual test effort and increases the quality by increasing the test coverage. For a single build time saved is 61.5 manual hours for a single application on one operating system using automation for localization testing. The framework designed for automation is more flexible for further enhancements of scripts. Scripts can run in an unattended mode which in turn saves the time and human effort. Automation for localization is developed in a generic framework which can be extended further with slight modifications, which can then be used for localization testing for other applications. This work can be extended to test the strings correctness for warning messages also.

\section{REFERENCES}

1. Zhi Quan Zhou ,Automated Software Testing and Analysis: Techniques, Practices and Tools School of IT \& Computer Science, University of Wollongong, Bernhard Scholz School of Information Technologies, The University of Sydney.

2. Grady Booch, James Rumbaugh, Ivar Jacobson, The Unified Modeling Language User Guide.
3. Ian Sommerville, Software Engineering, Ninth Edition; Addison-Welsey

4. http://msdn.microsoft.com/en-us/library/dd286726.aspx

5. http://blogs.msdn.com/b/mathew_aniyan/archive/2009/11 /05/tutorial-coded-ui-test-beta2.aspx

6. Jussi Kasurinen, Ossi Taipale, and Kari Smolander, Software Test Automation in Practice: Empirical Observations, Department of Information Technology, Laboratory of Software Engineering, Lappeenranta University of Technology

7. http://msdn.microsoft.com/enus/magazine/hh875174.aspx

8. http://www.articlesontesting.com/2011/04/write-text-logfor-coded-ui-testing-in.html

9. http://www.dotnetcurry.com/ShowArticle.aspx? ID=702

10. http://codedui101.blogspot.com/

11. Malik Jahan Khan, Abdul Qadeer, Shafay, Software Automated Testing Guidelines

12. http://blogs.msdn.com/uitest-framework-in-visual-studio2010-part-1.aspx

13. http://en.wikipedia.org/wiki/Software testing

\section{AUTHORS PROFILE}

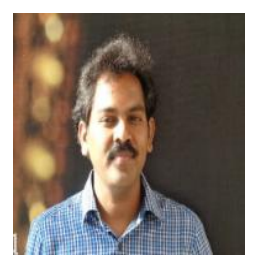

GopiChand.Merugu received Ph.D. in Computer Science \& Engineering from JNTUA, Anantapur, India and he received his M.Tech. in Computer Science \& Engineering from the same university. He received B.Tech. degree in Information Science \& Technology from Nagarjuna University, India. $\mathrm{He}$ is Professor \& Head, department of Information Technology Vardhaman College of Engineering, Hyderabad. He is a member of IEEE,CSI and IAENG. 